\title{
The Use of Froth Flotation for Selective Separation of Plastic Wastes from Soil
}

\author{
Kofi Moro and Dorothy A. Dechie
}

\begin{abstract}
In recycling of plastics, unless the goal is to form composites or materials having special properties, it is not advisable to mix plastics of different kinds because of the differences in their molecular weights and chain lengths. Hence, there is the need to separate these plastics when they are mixed before recycle can be done. This project investigated the selective separation of Polypropylene (PP), Polystyrene (PS) and Polyethylene terephthalate (PET) plastics out of soils using froth flotation. Pulverized samples were prepared from postconsumer plastic sources (PP, PS and PET) and soil and mixed uniformly to form a composite sample. The composite sample was subjected to froth flotation. Two tests were performed. A first test, where there was no addition of a depressant (tannic acid), and a second test, where there was addition of tannic acid to depress some of the plastics in order to selectively separate them. Recoveries from each test work indicated that, plastics are naturally hydrophobic and can be floated out of soils without modifying their surface properties. However, selective separations of the plastics were achieved when tannic acid was used to modify the surface properties of the plastic types.
\end{abstract}

Index Terms - Froth flotation, Polypropylene, Polystyrene, Polyethylene terephthalate, Tannic acid.

\section{INTRODUCTION}

Plastics are synthetic materials of high molecular mass that are malleable and are mostly obtained from petrochemicals. Plastic materials have rapidly replaced materials such as metals, glasses, ceramics etc., in their usage especially in packaging. This is due to their lower cost and higher durability compared to the other materials [1].

Urban plastics can be mostly attributed to increasing plastics production and consumption. Due to the rapid usage and disposal rate of plastics, wastes from plastics have become a major issue in terms of environmental sustainability and solid waste management.

Landfills, incineration for energy production, reuse and recycling are global actions and methods used to manage waste plastics disposal. However, urban waste fields commonly known as refuse dumps tend to retain plastics, which are recyclable.

Many major cities, especially in developing countries like Ghana, India and Brazil have slums and shanty towns, which generate massive amounts of wastes [7].These waste fields, can span many square meters because of limited resources to manage them. In most cases, the major component of these waste fields is plastic materials. As cities expand and the need to build new settlements and other infrastructure increases, there is always a need to move these massive waste fields, which most likely end up in landfills.

In order to manage the problems associated with urban waste fields, there is the need to separate these plastic wastes incorporated in the soil. Various researches have address numerous ways of separating mixture of different plastics. However, no or little work is done on the selective separation of mixture of different plastics and soil. This project however, intends to use flotation to selectively separate mixture of different waste plastics from soils, based on the different densities and flotabilities of various plastics.

Froth flotation is a well-known mineral processing method for the physical separation of minerals based on the hydrophobicity and hydrophilicity nature of different minerals. Hydrophobic minerals attach themselves to air bubbles and are carried to the surface of the flotation cell and recovered as floated products in mineral-water slurry. The hydrophilic minerals however stay in the liquid phase and are recovered as the sunk products [3]. Minerals or materials with same or similar physical properties (e.g. density, floatability, etc.) need surface modification by chemically treating the minerals to selectively change their properties (hydrophobicity) to achieve the desire separation [4]. This can be achieved by chemical conditioning using appropriate flotation reagents.

The hydrophobic nature of plastics, make it imperative for surface chemical conditioning to ensure that, one or more plastic types become hydrophilic while the remaining plastics are kept hydrophobic to obtain the selective separation of mixture of plastics by froth flotation. Selective wetting with wetting agent is one of the chemical conditioning approaches [4].

Previous papers published by various researchers indicate that, aside hydrophobicity, the shape and size of plastic particles is one of the controlling factors in plastic flotation [2], [4], [8]-[12].

Reference [1] published a paper on the controlling factors of plastic flotation which indicates importance of kinetics knowledge in the evaluation of froth flotation of plastics. It was concluded that, the kinetics of depressor concentration and air flow rate played a vital role in plastic flotation [1].

Several publications made use of methyl cellulose, tannic acid, saponin, sodium lignin sulfonate and calcium lignin sulfonate as depressors for plastic flotation [4], [8]-[10], [13].

In this project, tannic acid was used as the depressor to study the selective separation of post-consumer plastic mixtures from soil by froth flotation method. This work did

D. A. Dechie, TU Bergakademie Freiberg, Germany.

(e-mail: Dorothy-Alimah.Dechie@ student.tu-freiberg.de).
Submitted on May 13, 2021.

Published on June 28, 2021.

K. Moro, TU Bergakademie Freiberg, Germany.

(e-mail: Kofi.Moro@student.tu-freiberg.de). 
not study the effect of air flow rate, size and shape of plastic particles on flotation recovery.

\section{EXPERIMENTAL PROCEDURE}

\section{A. Materials}

A mortar and pestle was used to pulverize the melted plastics and lump of soil and dry sieved to particle size range between $+2 \mathrm{~mm}$ and $-2.36 \mathrm{~mm}$ using screens. An electronic scale balance was used to weigh the masses of the soil and the pulverized plastics. Denver flotation cell was used in the flotation of the soil and plastic samples. Three types of granulated plastics from Tarkwa municipality waste field; Polystyrene (PS, transparent white), Polyethylene terephthalate (PET, cream) and Polypropylene (PP, ash). The plastics differed on colour, which facilitated separation through manual sorting at the end of each flotation test. The theoretical density (not measured; obtain from literature) of the plastics ranged from $0.86 \mathrm{~g} / \mathrm{cm}^{3}(\mathrm{PP}), 0.96 \mathrm{~g} / \mathrm{cm}^{3}$ (PS), and $1.372 \mathrm{~g} / \mathrm{cm}^{3}$ (PET), [1], with particle size range of -2.36 to $+2 \mathrm{~mm}$ obtained by dry sieving. The flotation experiments were carried out by using, $0.1 \mathrm{~g} / \mathrm{L}$ concentration of tannic acid (wetting agent) and Methyl isobutyl carbinol (MIBC); frothing reagent [6].

\section{B. Pulverizing of Plastics and Soil}

The plastics obtained was shredded into smaller pieces, cleaned and allowed to dry for some times under atmospheric conditions. This was to enhance uniform melting of the plastics and to ensure that melting time was reduced. The shredded plastics were placed in an aluminum saucepan and heated on a gas stove until everything was melted. The molten plastics were allowed to solidify after cooling. The solidified plastics were pulverized by manual grinding (mortar and pestle) and screened to a particle size range between $+2 \mathrm{~mm}$ and $-2.36 \mathrm{~mm}$. Lump of soil (clay) was dug from around University of Mines and Technology, Tarkwa minerals laboratory. The lump of soil was sun dried for 2 hours to remove as much moisture from it. It was then ground and sieved to remove any foreign materials present in the soil.

\section{Preparation of Plastic-Soil Composite}

Two different composite samples were formed. One composite sample was formed by combining only the plastics (no soil), and the other formed by combination of all the plastic samples and the soil and were labelled CS1 (10 g each of the pulverized plastics; total weight $30 \mathrm{~g})$ and CS2 (10 g each of the pulverized plastics and the soil; total weight $40 \mathrm{~g}$ ), respectively (Fig. 1).

\section{Flotation Test}

The flotation tests were performed in a Denver flotation cell with $3 \mathrm{dm}^{3}$ of volume with impeller rotational speed of 600 rpm. Normal tap water was used throughout the flotation experimental tests with $\mathrm{pH}$ and temperature maintained at natural values (i.e., 7.4 and $25{ }^{\circ} \mathrm{C}$, respectively, with insignificant variations). This was possible by a periodic measurement of the respective parameters. The background for the selection of tap water was the fact that, plastics depression is done in the presence of cations [2].

In the flotation tests, water was introduced into the flotation cell and the impeller switched on with a rotational speed of
$600 \mathrm{rpm}$. The sample was then introduced into the cell and allowed to agitate for 3 minutes. The tannic acid (depressor) of constant concentration of $0.1 \mathrm{~g} / \mathrm{L}$ was added to the slurry in the cell and allowed to condition with the particles for 6 minutes. $2 \mathrm{ml}$ of MIBC (frother agent) was added and conditioned for 2 minutes after the fourth minute of tannic acid conditioning. After tannic acid conditioning, the air valve was opened to release air into the cell and flotation began [5]. Three different flotation tests, (Test 1 (T1), Test 2 (T2) and Test 3 (T3)) were conducted under the following conditions: T1: flotation of CS2 with no tannic acid addition (without depressor conditioning), T2: flotation of CS1 with tannic acid addition (with depressor conditioning) and T3: flotation of CS2 with tannic acid addition (with depressor conditioning).

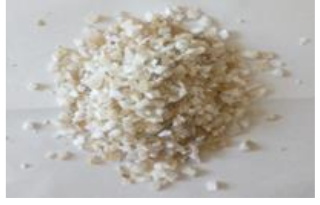

(a)

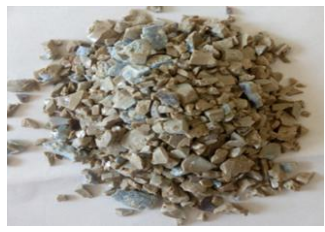

(c)

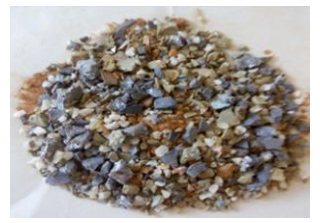

(e)

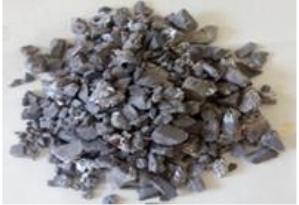

(b)

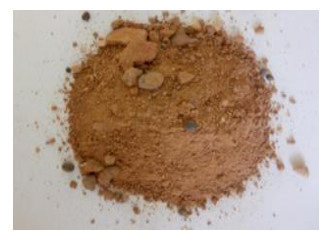

(d)
Fig. 1. Photographs of pulverized samples: (a) PS ,(b) PP, (c) PET, (d) Soil, (e) Plastic-soil mixture.

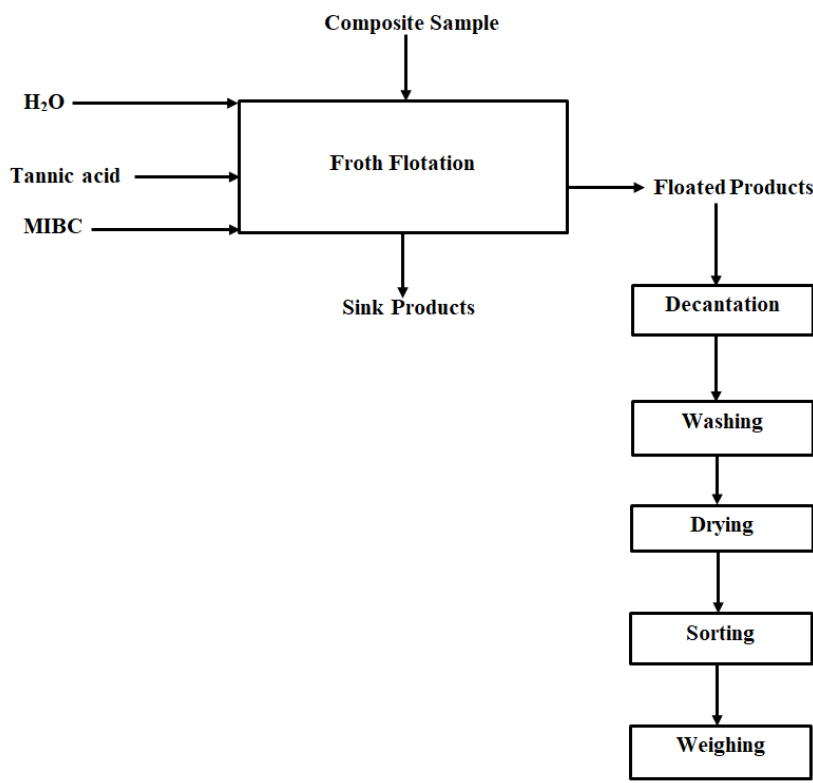

Fig. 2. Experimental procedure flowsheet. 
In each flotation test, the floated products were scooped after every minute of flotation time, for five consecutive times; hence 5 floats and one sink products were collected. Both float and sink products were collected, decanted, washed and sun dried for 2 hours. The different plastics and soil in each product were manually sorted (which was possible because of the different colours of the individual plastic particles) and weighed.

\section{RESULTS AND DISCUSSIONS}

\section{A. Plastics separation from Soil}

Fig. 3 shows the amount of plastics recovered from the soil-plastics mixture with time. The experiment was carried out in the absence of tannic acid (depressant). It can be seen that, the flotation of all plastics was almost complete and very fast. In less than a minute more than $95 \%$ recovery of all plastic type was attainable. This was indicative of the fact that plastics are typically hydrophobic in nature, thus, they will float on their own in water. Works done by [4] reported a similar trend for floatability of plastics in water. Although higher recoveries of plastics were realized, $100 \%$ recovery for any of the plastic type was not possible in the equipment used; Denver flotation cell. This could be attributed to the impeller surge as result of the particle size of the plastics used; $+2 \mathrm{~mm}$ and $-2.36 \mathrm{~mm}$. The difference in recoveries of the individual plastics maybe attributed to their contact angles (PP; $102.1^{\circ}, \mathrm{PS} ; 87.4^{\circ}$ and PET; $74.2^{\circ}$ ). The higher the contact angle, the higher the floatability [4]. Throughout the flotation period, it can be seen clearly that the soils did not float depicting the fact that plastics can be separated out of soils using flotation.

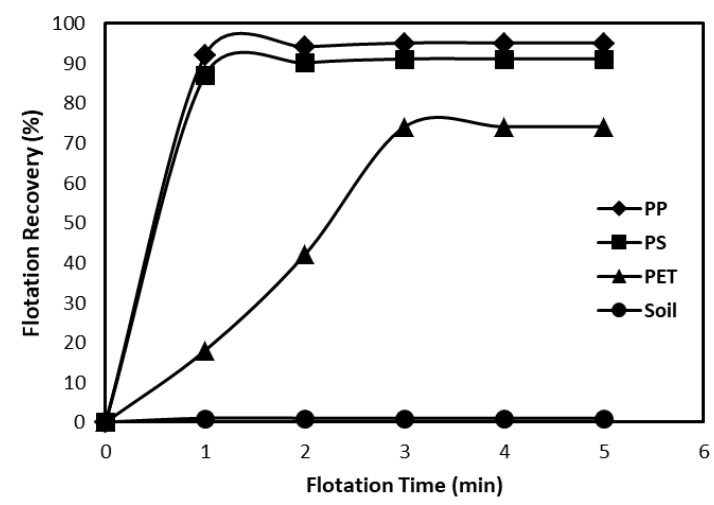

Fig. 3. Graph of flotation recovery against time: ( $40 \mathrm{~g}$ mixture of plastics and soil, no tannic acid, $2 \mathrm{ml} \mathrm{MIBC}$ in $3 \mathrm{dm}^{3}$ flotation cell at $600 \mathrm{rpm}$ for 5 minutes).

\section{B. Effect of Tannic Acid on Selective Separation of Individual Plastic Types}

The effect of tannic acid addition on the separation of each plastic type with respect to time is presented in Fig. 4. Tannic acid was added in the second test, which was made up of only plastics. The addition of tannic acid $(0.1 \mathrm{~g} / \mathrm{L})$ decreased the recovery rates of PS and PET to $86 \%$ and $8 \%$ respectively at the end of the fifth minute. Although the actual mechanism for this occurrence was not determined it could be attributed to an alteration (lowering) of the contact angle by the addition of tannic acid as reported by other workers [1], [4]. The lower the contact angle the more difficult it will be for the plastics to float. PP however remained almost unaffected by the addition of tannic with $98 \%$ recovery achieved at the end of the fifth minute.

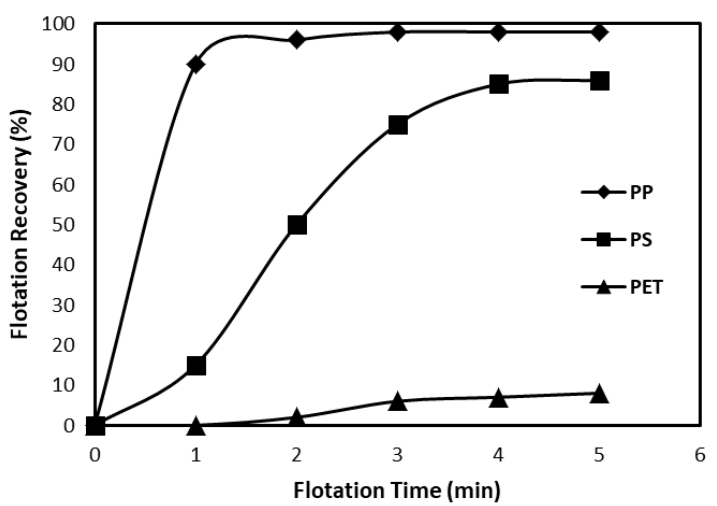

Fig. 4. Graph of flotation recovery against time; $(30 \mathrm{~g}$ mixture of plastics with $0.1 \mathrm{~g} / \mathrm{L}$ tannic acid, $2 \mathrm{ml} \mathrm{MIBC}$ in $3 \mathrm{dm}^{3}$ flotation cell at $600 \mathrm{rpm}$ for 5 minutes).

\section{Selectivity of Plastic Separation}

Fig. 4 confirms that, tannic acid actually influenced the selective separation of plastics from plastic mixtures. In this regard, there was the need to also confirm the acid effect on the selective separation of the plastic mixtures from soil. Fig. 5 shows the recoveries of the various plastics from the plasticsoil mixture in the floated products. This shows the distinctive separation of the individual plastics from soil. Based on their individual recoveries, a high degree of selectivity was realized. Fig. 6 shows the recoveries of the plastics at every flotation time, which clearly shows that, in the first minute, the recoveries for PP, PS, PET and soil were $87 \%, 10 \%, 0 \%$ and $0 \%$, respectively. This shows $100 \%$ selectivity in the separation between PP/PET and PP/soil: likewise, the separation between PS/PET and PS/Soil. However, that was not realized in the separation between PP and PS although some degree of selectivity was achieved. In the second minute, the recoveries for PP, PS, PET and soil were $6 \%, 38 \%, 2 \%$ and $0 \%$, respectively. This also shows some degree of selectivity in the separation of the various plastics. Similar trends were seen in the third and fourth minutes. In the fifth minute, about $0 \%$ recovery was observed for all the plastics. This showed that, all the hydrophobic components of the plastics had floated, and the remaining plastics (hydrophilic components) were supressed.

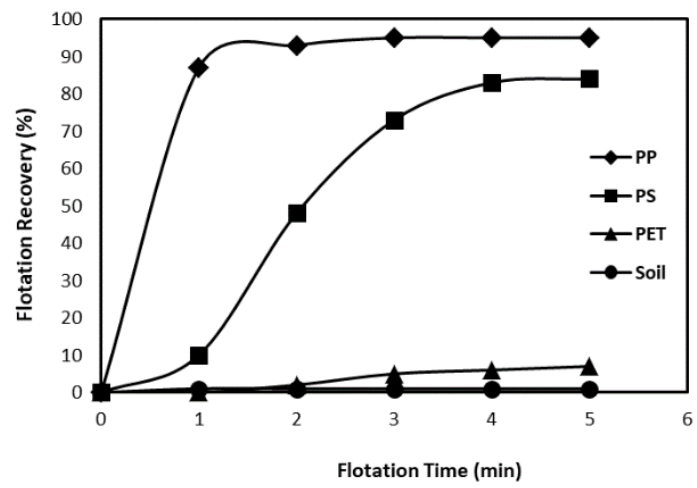

Fig. 5. Graph of flotation recovery against time; (40 $\mathrm{g}$ mixture of plastics and soil with $0.1 \mathrm{~g} / \mathrm{L}$ tannic acid, $2 \mathrm{ml} \mathrm{MIBC}$ in $3 \mathrm{dm} 3$ flotation cell at $600 \mathrm{rpm}$ for 5 minutes). 


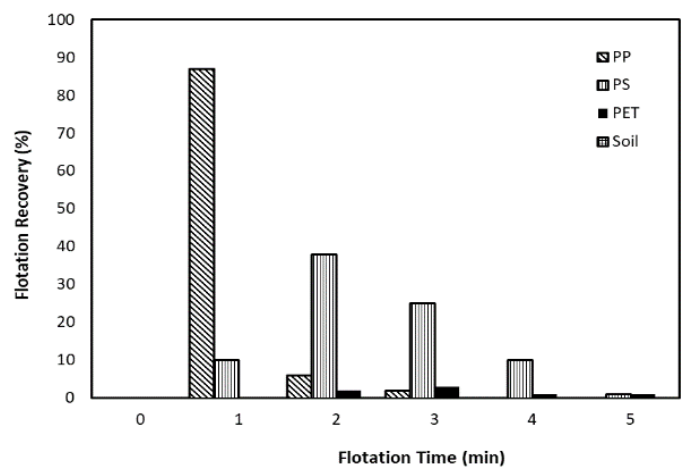

Fig. 6. Bar chart of flotation recovery of plastics at every minute of flotation time.

\section{CONCLUSION}

Froth flotation experiments were carried out with samples of PP, PS, PET, and soil where tannic acid was used as depressant. The higher recoveries achieved in the absence of tannic acid indicated that plastics are naturally hydrophobic, that is, plastics can be floated out of soils without the need for a reagent. However, a depressor is necessary to aid the selective separation of the plastics by way of influencing their floatability. In the presence of tannic acid $(0.1 \mathrm{~g} / \mathrm{L})$, PET was significantly depressed and almost reported as sinks while PP and PS were recovered as products. From the results, it can be concluded that, froth flotation has a good possibility to be used in the selective separation of plastics from polymer-soil mixture. In this respect, there will be no need for a two-stage separation process; where there would be a first stage separation of plastics from soil based on hydrophobicity nature of plastics and a second stage selective separation of the individual plastics with depressor conditioning. Nevertheless, a selective separation of plastics from soil can be achieved simultaneously by a one stage separation process via froth flotation with depressor conditioning.

\section{ACKNOWLEDGMENT}

The authors are most grateful to the Minerals Engineering department of the University of Mines and Technology, Tarkwa, Ghana for making available reagents and equipment in the Minerals Processing laboratory. We also thank Assoc. Prof. James Ransford Dankwah and Dr. Bellson Awatey for his technical assistance.

\section{REFERENCES}

[1] M. Censori, F. La Marca, and M. Carvalho, "Separation of plastics: The importance of kinetics knowledge in the evaluation of froth flotation," Waste management, vol 54, pp. 39-43, August 2016.

[2] N. Fraunholcz, "Separation of waste plastics by froth flotation - a review, Part I." Minerals Engineering, vol 17, pp. 261-268, February 2004.

[3] S. Kawatra, and P. Darling, "Fundamental principles of froth flotation," SME Mining Engineering Handbook, vol 2, pp. 1517-1531, February 2011.

[4] F. Pita, and A. Castilho, "Separation of plastics by froth flotation. The role of size, shape and density of the particles," Waste Management, pp. 91-99, February 2017.

[5] F. Pita, and A. Castilho, "Plastics floatability: effect of saponin and sodium lignosulfonate as wetting agents," Polimeros, October 2019.
[6] F. Pita, and A. Castilho, "Separation of PET from other plastics by flotation combined with alkaline pretreatment," Polimeros, November 2020.

[7] Urban and economic world revision guide 1 (April 2021), Available: https://resources.finalsite.net/images/v1553547261/sydenhamlewisha mschuk/qk3ips4szvqukrwnpkfe/UNIT-2-URBAN-AND ECONOMIC-WORLD-REVISION-GUIDE-1.pdf.

[8] H. Shen, E. Forssberg, and R.J. Pugh, "Selective flotation separation of plastics by particle control," Resour. Conserv. Recycl., vol 33, pp. 3750, August 2001.

[9] H. Shen, E. Forssberg, and R.J. Pugh, "Selective flotation separation of plastics by chemical conditioning wit methyl cellulose". Resour. Conserv. Recycl., vol 35, pp. 229-241, June 2002.

[10] J. Shibata, S. Matsumoto, H. Yamamoto, E. Lusaka, 1996. "Flotation separation of plastics using selective depressants," Int. J. Miner. Process., vol 48, pp. 127-134, December 1996.

[11] R.D. Pascoe, and Y.Y. Hou, "Investigation of the importance of particle shape and surface wettability on the separation of plastics in a LARCOMEDS separator," Miner. Eng., vol 12, pp. 423-431, April 1999.

[12] F. Burat, A. Güney, and M.O. Kangal, "Selective separation of virgin and postconsumer polymers (PET and PVC) by flotation method," Waste Management, vol 29, pp. 1807-1813, June 2009.

[13] M.O. Kangal, "Selective flotation technique for separation of PET and HDPE used in drinking water bottles," Miner. Process. Extr. Metall. Rev., vol 31, pp. 214-223, September 2010.

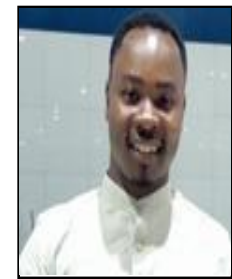

Kofi Moro obtained BSc (Minerals Engineering) from University of Mines and Technology, Tarkwa, Ghana (2017). He is currently pursuing his master degree in Sustainable Mining and Remediation Management at TU Bergakademie Freiberg, Germany. His research interest includes sustainable mining, optimization of metal recovery, Reprocessing and management of industrial waste and hydrometallurgy.

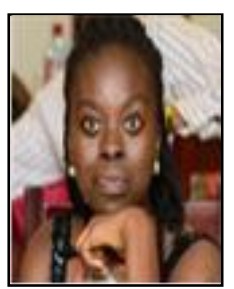

Dorothy Alimah Dechie obtained BSc (Mining Engineering) from University of Mines and Technology, Tarkwa, Ghana (2018). She is currently pursuing a joint master degree in Sustainable and Innovative Natural Resources Management at (Ghent University, Belgium, Uppsala University, Sweden and TU Bergakademie Freiberg, Germany). Her interest lies in, sustainable mining and biohydrometallurgy. 